\title{
Destination and Enterprise Management for a Tourism Future
}

Larry Dwyer, Deborah Edwards, Nina Mistilis and Carolina Roman

\begin{abstract}
A key element of a successful tourism industry is the ability to recognize and deal with change across a wide range of key factors and the way they interact. Key drivers of global change can be classified as Economic, Social, Political, Technological and Environmental. This paper explores the way in which these key drivers could affect the global tourism industry to the year 2020. An exploration of these trends allows important change agents, on both the supply side and the demand side of tourism, to be highlighted and discussed. In response, innovative strategies can be formulated by destination managers and tourism operators to avoid strategic drift for their organisations and to develop tourism in a sustainable way.
\end{abstract}

\section{Introduction}

Since tourism is essentially integrated with other sectors in the economy, tourism trends cannot be considered in isolation from key drivers that will shape the world of the future. Some trends operate at a global level and may be referred to as mega trends. These include: the Global Economy and Globalisation; Political; Demographics; Natural Resources and Environment; and Science and Technology. PEST analysis was developed by Fahey and Narayan (1986) in order to categorize different forces of change and trends on a general level, decomposing the macro environment into four segments - Political, Economic, Social, and Technological. Subsequently, an environmental segment was added, completing the model. The STEEP model emphasizes that the macro environment is a system of interrelated parts that affect one another. This framework is useful in identifying and structuring some of the more important drivers of change and trends affecting tomorrow's tourism and travel. These changing realities make up the strategic context within which long-term tourism industry policies, planning and development are made. All such trends comprise the external environment in which consumers make travel related decisions, such as where to go, how to go, what to do and how much to spend.

What changes are taking place globally that will influence the types of experiences that tourists seek in the future? The answers that destination managers and tourism operators give to this question will influence the types of products and services that are developed today to match future industry needs. This flags the importance of innovation to the tourism industry. Those destinations and individual operators that make decisions on the supply side that do not match changing 
customer needs will suffer the phenomenon of 'strategic drift' (Johnson and Scholes 1997). Strategic drift occurs when an organisations strategy gradually moves away from addressing the forces in the external environment with no clear direction.

The coming decade and a half should see major shifts in the leisure and tourism environment reflecting changing consumer values, political forces, environmental changes and the explosive growth of information and communication technology. The challenge for tourism stakeholders in both the private and public sectors is to transform themselves through innovative approaches to achieve and maintain competitive advantage for their organizations.

Many associations and institutions publish trend data with a discussion of the implications of those trends (PATA 1999, Yesawich 2000). These reports however lack coherence, making it difficult for the tourism industry to make sense of a large amount of data in a range of reports. Additionally these reports often fail to acknowledge or explain the forces that drive the projected changes, the implications of those changes for different stakeholders (eg. tourists, industry, community, government), or the relative impact of the different factors on tourism and other industries that have links with tourism. It is important to know how world events influence consumers and suppliers of goods and services and consequently how this shapes tourism. There is increasing competition in the tourism and hospitality industries - between destinations worldwide (between established markets and from new markets), between destinations domestically, and between firms within a destination. Achieving competitive advantage in times of rapid change requires tourism stakeholders to have a clear understanding of the direction of change and its implications for business or destination management. Since tourism is essentially integrated with other sectors in the economy, tourism trends cannot be considered in isolation from key drivers that will shape the world of the future. This paper argues that in a world in which the broad global trends can be predicted to some extent, their influences on tourists and tourism organisations (public and private) can be identified. In these circumstances, research can play a major role in assisting strategy formulation by suppliers of the tourism product -the tourism destination and enterprise.

The greater the reliance on tourism research into broad trends and local issues, the greater the potential to reduce the risks of misallocating resources to uncompetitive areas and towards improving outcomes by translating the implications of predictions for destination and enterprise management and suggesting strategies to 'reduce the risk' of their impacts. The challenge for tourism stakeholders in both private and public sectors is to account for these changes pro-actively to achieve and maintain competitive advantage for their organizations. If they meet these challenges, then they will 'reduce the odds' of strategic drift. The following sections explore the way in which the key drivers could affect the global tourism industry to the year 2020 . 
The paper first identifies the major forces driving global change to 2020 through an analysis of key public documents. Second, to understand the ways in which these trends influence tourism organisations and tourist values and attitudes, the paper presents a model displaying the main causal links between broad external forces and the implications for tourism stakeholders. Third, the paper discusses the relevance of research as an input into organisational decision making and strategy formulation. Fourth, since the emphasis of the study is on actionable results, the authors recognise the importance of industry input into strategy formulation. This was enabled via a series of workshops allowing practitioners to assess recommendations for new product development and various aspects of enterprise and destination management.

\section{Global Trends Affecting Tourism}

After an extensive literature review of megatrends in the general (non tourism) literature was undertaken, that which could affect both the demand and supply sides of the global tourism was selected. The National Intelligence Council (NIC, 2004), in close collaboration with United States Government and a wide range of external experts, has worked to identify global drivers and trends that will shape the world of 2020. This literature along with the UNWTO travel forecasts informs much of this research and enabled identification of those trends at a global level that will have significant implications for public and private sector tourism providers and tourists themselves. Five key drivers appear to underpin the general trends - economic (including globalisation), political, social, environmental and technological (Butler and Jones 2001, Cetron 2001, WTO 2002, Dwyer 2004, Stern 2006).

\section{Globalisation and Long-term Economic Trends}

Globalization, the growing interconnectedness reflected in the expanded flows of information, technology, capital, goods, services, and people throughout the world, is seen by many as an overarching "mega-trend," a force so ubiquitous that it will substantially shape all the other major trends in the world of 2020. It is a product of the revolutions in telecommunications, computing, the growth of free trade, the decline of communism and the democratisation of financial markets. Increased international connectivity will continue to change the shape of modern life, further diminishing the constraints of physical boundaries and extending the geographical scope of social networks. It is a powerful force shaping national and regional economies, which are linked and interdependent as never before. For the long term, continued moderate-to-good rates of global economic growth are anticipated by major global financial and economic institutions. Most 
projections indicate that the world economy is likely to continue growing impressively at least over the next decade and a half.

Still, there are possible brakes to growth. They include downturns in key economies with attendant spill over implications for other economies, disputes over international economic rules, and situations of unequal growth prospects and distribution. The countries and regions most at risk of falling behind economically are those with endemic internal and/or regional conflicts and those that fail to diversify their economies.

\section{Social trends}

Unprecedented demographic shifts are having profound effects on virtually every social institution. North America, Australia, and New Zealand - traditional magnets for migrants - will continue to have the highest rates of population growth among developed countries, with annual population growth rates between 0.7 percent and 1.0 percent (NIC 2004). The growing world population is ageing, with increasing longevity, mostly in rapidly expanding urban areas (UNWTO 2002; NIC 2004).

"Baby boomers" will demand products and services that cater to their aging needs (Weston, Qu, \& Soriano, 2001). Businesses will need to develop ways for 'senior or 'older' citizens to stay in the work force longer. There is a worldwide trend towards urbanisation: the number of very large cities, megalopolises of more than 10 million people, will double to about 30 and their management will be a significant new problem (NIC 2004). As a consequence travellers will tend to favour holidaying away from crowds, and are spoilt for choice globally. Subsequently cities will need to work hard to illustrate that they are destinations that are worth visiting for more than a short break, and for more than one visit (Ulbrick, 2006). High standards of public health in developed countries have contributed to increased longevity. This will result in increased demand for a combination of health and travel products and in developed countries there will be a blurring of working life and retirement (Weston, Qu, \& Soriano, 2001). Increased international travel will fuel the emergence and spread of infectious diseases (NIC, 2004).

Changing Social Structures will continue, with generation $Y$ the largest and most diverse demographic. Age complexity is occurring (Profound and Duerbeck 2005). Children are growing up faster but more adults want to be teenagers. The aspirational age of 12 year olds is 17 . Products for children will need to have cool teen attributes. Adults are behaving more like teenagers in dress sense, eating habits, interests and pastimes (Profound and Duerbeck 2005). 
Tapping into the mindset of target segments, to determine how they think - not just how they behave will be important for marketing success.

An increasing number of people will be money rich-time poor and increasing demand for customized products. Consumers in a search for a wider meaning will seek newer/richer/deeper experiences. People will be more experimental, but won't give a second chance to a product or service that fails to satisfy. In terms of values and lifestyles, ethical consumption will continue increasing. The distinction between work and leisure will blur, society and men will become more feminised with women having increasing influence on all the key decisions.

Increasingly education will be a determinative of success for destinations and businesses. This includes innovative businesses that are well attuned to their customers needs, and staffed with highly educated workers valued as 'human capital' and organisations with external knowledge focusing on organizational culture that enshrines life-long learning. It also includes social infrastructure that maximises opportunities for individuals and businesses to be innovative, learn and develop knowledge, skills and access knowledge age services.

\section{Political Trends}

Political trends can be grouped under four themes - international power, security, conflict and health. In terms of international power, the USA is likely to remain an important influence but with its relative power position eroded and an enlarged Europe will increase its weight internationally. Japan faces an aging crisis which could challenge its regional status. China and India will emerge as new major global players and transform the geopolitical landscape. Russia still has international potential due to its gas and oil, but will be limited by social and political challenges (NIC 2004).

In terms of security, the key factors that spawned international terrorism show no signs of abating over the next 15 years, and the threat of terrorism is likely to become more decentralized, due to internet use (NIC 2004). Today, the world faces the challenge of confronting networked terrorism. The issues and fallout from ongoing heightened security and terror will continue, with an expected increase in cyber terrorism. Security issues will herald stricter border controls, thus creating barriers or deterrents to tourism. In this environment, the need for enterprise and government cyber security and biosecurity will grow. Whole destination and individual operators must sustain safety and security, including cyber security and biosecurity. Whilst these concerns have encouraged the growth of 'enclave tourism' such strategies need to be re-examined to ensure resorts are not targeted. For the tourist, the destination image based on safety is increasingly important: real and perceived risks constrain tourist behaviour. There is also a need for investor 
and insurance drivers to decrease perceived risk. All these factors will lead to increase security costs for international commerce.

Regional conflicts are likely amongst Lesser Developed Countries (NIC, 2004); another global war is unlikely. Islam will continue as a focus of global dissent and the Middle East conflicts resulting in increased fuel costs of travel. The gap between the "haves" and "have-nots" will widen without support policies.

\section{Environmental trends}

Contemporary environmental problems will persist and in many instances grow over the next 15 years and beyond. All countries are likely to face intensified environmental problems as a result of population growth, economic development, and rapid urbanisation (Dwyer, 2004). The major environmental trends include climate change, natural resources (energy, water, and land-use), biodiversity and other environmental trends of relevance, including ozone depletion and land salinity (UNEP 2002). Unlike the other megatrends discussed in this paper which assume a 15 year time horizon, forecast changes in environmental variables often extend to the end of this century.

Climate change will continue to be a most concerning and controversial environmental challenge of our time. It is generally described as significant changes in the long-term average weather patterns, which in turn shifts the climatic characteristic of a region over time to new conditions. These significant changes can manifest themselves as shifts in atmospheric and ocean water temperatures, thus creating new conditions for air temperatures as well as rates of precipitation and evaporation, and other weather variables such as wind and storm patterns. According to the United Nation's Intergovernmental Panel for Climate Change, a great majority of climate models predict a near-surface warming trend under the influence of rising concentrations of greenhouse gases in the atmosphere. Greenhouse gases and climate change are not unprecedented phenomena, since climatic variation has been part of the earth's system throughout geological time scales. However, one of the major factors in the current climate change trend is the contribution from continued reliance on and consumption of fossil-fuel based energy sources. What is unprecedented, are the rates at which these greenhouse gases are continuing to be released into the atmosphere.

The Stern Report (2006) states that the benefits of strong, early action to invest in reducing emissions, mitigation, and adaptation capacity will considerably outweigh the costs incurred today. The general warming trend across the globe, which is currently observed as climate change, can 
have many environmental impacts which are transboundary i.e. across one or many political and geographical borders, and likely to vary greatly between regions, continents, and climate zones. Some of the impacts from temperature changes can include sea-level rise, changes to ocean currents, accelerated rates of glacial melt in the polar regions, and loss of snow cover and permafrost. Other impacts include alteration of precipitation patterns such as rainfall, and likelihood of increased frequency and intensity of extreme weather events such as storms and drought conditions.

Due primarily to population growth and economic development, the biological and physical resources of Earth are being degraded and exhausted. Natural resources which are affected include agriculture and food, energy, water, and land use. The main issue for energy is the inevitable rise in the price of oil, which impacts on economies. Traditional suppliers in the Middle East are also increasingly unstable. Thus sharper demand-driven competition for resources, perhaps accompanied by a major disruption of oil supplies, is among the key uncertainties. To date, production has kept increasing, however new discoveries already appear to be declining. The global economy should continue to become more energy efficient to 2020 .

World consumption of water is increasing at twice the rate of population growth. Over the next 30 years the number of countries facing water shortages will double. Where water supply is currently dominated by melting snow or ice, an increase in surface temperatures is expected to produce less winter precipitation. With increasing extensive and intensive land use for agricultural purposes, significant degradation of arable land will continue as will the loss of tropical forests. The loss of biodiversity is increasing due to population pressure and loss of habitat, pollution and over-hunting. In terms of other environmental trends, depletion of the ozone layer, more commonly referred to as the "ozone hole", has been attributed to the release of CFCs into the atmosphere thus accelerating the depletion of ozone in the Earth's stratosphere. The ozone layer protects the earth's surface from ultraviolet radiation. Increasing soil salinity degrades affected land for agriculture and other productive land-uses.

\section{Science and Technology Trends}

The world will encounter more quantum leaps in information and communication technology (ICT) and in other areas of science and technology. Technology is by far the foremost management tool in achieving results and competitiveness in a business operating environment. Business to business e-commerce (B2B) will grow much faster than business to consumer e-commerce (B2C). Networking is the most important element of the ICT revolution because synergies between 
departments and organisations reduce labour cost, increase efficiency and enable flexible and differentiated product development.

New Internet technologies are agents of the consumer. WEB2.0 is currently most common - the term used to describe phenomenon of convergence of societal trends (eg internet penetration) and technology (Ajax, blogs, wiki) making applications run more like desk top applications. With the Web2.0 boom, websites with user generated content exploded, increasing collaborations between fellow online consumers. Generation $Y$ views sites with video clips, opinions, chat rooms, groups, blogs - fundamentally where this age group 'lives'. Therefore destinations and operators need to integrate these online communities and product creating excitement in order better to reach their consumers: YouTube, Flickr, mySpace (61 million registered users) and Second Life.

E-communities may direct trends and 'advertise' for the destination /operator, so suppliers need to understand new media and marketing opportunities, not just traditional advertising, to analyse and respond to reviews of their products and services. However, the commentary of consumer groups needs structure, information quality, and trust to better underpin their value for the consumer.

Web3.0 or the 'semantic web' will introduce intelligence systems (AI) to the Internet which act as personal advisors - the business model now adopted by leading travel agents. This will close the gap between on and offline travel services as they have the capacity to provide tailored information to the potential tourist which travel agents do now. Thus Internet capability is advancing from simple online travel booking to advanced content and collaboration to Al.

ICT is fundamental to organisational competitive strategy. The key strategic question is how to deploy information technology for strategic advantage. Whilst the Internet provides better opportunities to develop distinctive strategic positioning, it must be used to build on 'proven principles of effective strategy'. Knowledge is increasingly recognized as essential to the competitive advantage of any organisation. It will become an even more important asset in economies and businesses.

\section{Relevance for Destination and Enterprise Management}

The findings have relevance conceptually and empirically. Each of the global trends has tourism relevance no single driver or trend will dominate; each to a greater and lesser degree influences the other and will have varying impacts in tourism destination different regions, countries and industry sectors. The drivers are not necessarily mutually reinforcing; in some cases, they will work at cross-purposes. Taken together they set the context in which the global tourism industry may be 
expected to develop to 2020. They provide a flexible framework to discuss and debate the future of tourism demand and supply and the type of tourism industry that will be successful in the future.

Until recently, the trends that appear to have received the most attention from researchers are economic and technological (Dwyer 2004). Herein, emphasis is placed on the three relatively neglected trends-political, social and environmental. For example the incidence of terrorism in the future is dependent on political trends (Tarlow 2002). A trend of particular relevance to tourism is that of global warming (Stern 2006). Also, social trends are affecting tourist values and needs (Cetron 2001). For all established and emerging markets, the values and attitudes of 'tomorrows tourist' have implications for the destination and for suppliers of tourism goods and services. Such trends importantly impact on outbound tourism and destination market share with implications for tourism management.

Faced with pressures for change, managers typically try to minimise the extent to which they are faced with ambiguity and uncertainty by looking for that which is familiar. This raises difficulties when strategically managing (future) change because it may be that the action required is beyond the scope of their core assumptions and routines. In essence the organisation does not understand the cause and effect of what is occurring in the external environment resulting in strategic drift. A major challenge for tourism organisations in the context of megatrends is identifying when their organisation is at risk of, or in a state of strategic drift. Those organisations that seek to stretch what they regard as their core competences to create new opportunities could also confront problems resulting in transformational change only when it is too late. It is noted that transformational change might be attempted through the innovation and development of entirely new products or services which seek to create new customer needs and expectations.

We may better understand the ways in which these trends influence tourism organisations and tourist values and attitudes, through a model displaying the main causal links between broad external forces and the implications for tourism stakeholders. Figure 1 depicts the proposed framework in which the megatrends would influence and impact upon the tourism industry. The five megatrends (economic, social, political, environmental and technological) influence three key tourism facets - the destination (destination management), enterprise (enterprise management) and tourist (values, needs, flows). As well the destination and enterprise on the one hand and the tourist on the other interrelate in their influence on new product development. The spheres of influences are graphically depicted in circular mode, indicating the dynamism of the situation.

The trends should guide decision processes and resource allocation. Each of these trends has sub-components as well as occasional counter trends. Only by understanding and acting upon reliable trend forecasts will the tourism industry be able to avoid the most common cause of bad 
decisions: misassumption about the external demographic, economic, political, and technological and natural environments. The megatrends discussed in this paper will have varying effects in different regions and countries. Some trends may be of more limited scope affecting particular industries, segments or even particular firms. Thus the destination and enterprise influence new product development, in turn themselves influenced by megatrends, whilst the tourist also influences new product development, in turn being influenced by these megatrends.

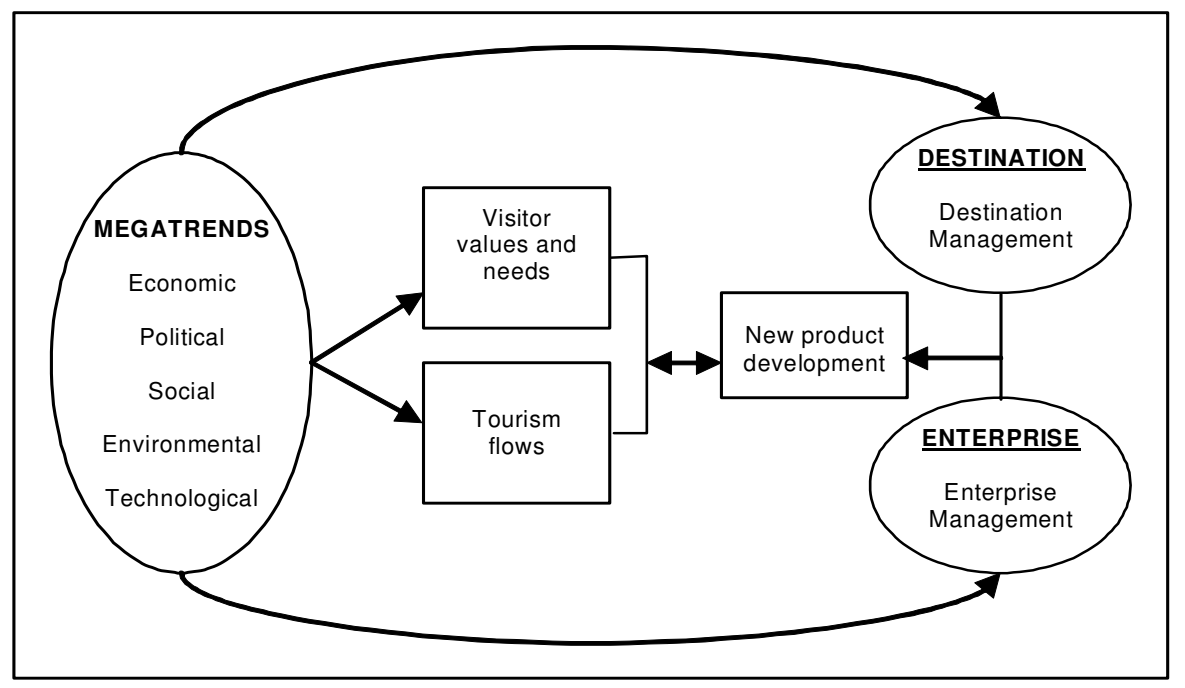

Figure 1: Influence of Megatrends on Tourism

Globalisation and long term economic trends for tourism will influence tourism in a number of ways. First, studies indicate that rising income is the most powerful generator of tourism flows. The deregulation associated with globalization will also positively influence inbound and outbound tourism flows. Second the diffusion of ICT drives globalization and can enhance the competitive advantage of destinations and tourism businesses. Third, more power will be obtained by the relatively small number of large global travel and tourism networks. Fourth destination choice will be determined by economic factors, the availability of time as well as perceived desirability. Finally the increased mobility of business will lead to high rates of growth in business travel.

In social trends for tourism, the increasing expectations of people will generate more demand for discretionary expenditure on travel and tourism. This demand in conjunction with other social changes will affect tourist characteristics and tourism flows. Travel and tourism will increasingly be factored into lifestyles, growth will be in holidays for the retired and for single people, holidays will be more specialised and visitors will demand more flexibility of travel plans. As more people live in urban environments the demand for nature based holidays will increase. 
There is significant relevance of the political driver for tourism. First, destinations perceived as less safe and secure will be avoided. Second, destinations that do not advance economically because of political constraints to growth will generate fewer outbound and domestic tourist numbers. Third, conflicts between countries will constrain tourism flows overall but can also benefit destinations perceived to be 'safe'. Fourth, conflicts in and around the Middle East have capacity to substantially increase fuel costs of travel. This impacts on both the demand for travel but also places increased pressures on suppliers many of which operate already on low margins. Fifth, the destination as a whole as well as the individual operators who deliver the tourism product must play a role in sustaining the safety and security of their visitors and collectively the destination. Tourism's vulnerability raises the need to have and effectively be able to implement disaster management strategies, particularly at the destination level. Finally marketers of destinations affected by real or imagined risk factors need to target tourists with a higher tolerance for risk.

Tourism is closely linked to the environment, underlining the latter's extreme importance. Climate change will influence which destinations will be preferred by tourists and which ones will cease to be as attractive and development of 'artificial' (indoor) environments for tourism may be expected to increase. Climate change could impact on the profitability of tourism through increasing energy use, seriously impacting on the 'bottom line' of operators. Tourism is transport-intensive and so it is heavily exposed to oil prices. In the face of declining stocks of oil, basic transport needs (eg. for economic development and commuting to work) may have precedence over discretionary transport needs such as recreational tourism. Ongoing high oil prices would be particularly bad for tourism long haul destinations. Also any resulting economic recessions will impact adversely on the tourism industry.

The most pervasive technological changes that will be applied to the tourism and recreation industry are both predictable and manageable. The success of tourism enterprises will continue to hinge on their efforts to add value to products and services through the use of technology producing competitive advantage. Using ICT, the most innovative tourism organizations and enterprises will redefine both their own structure and their relationships with their partner organizations. Interactive access to product offering via the Internet gives tourists unprecedented control over how they spend their time and money. Destinations and tourism organisations that do not embrace the Internet and make the associated investments in information technology, expert systems and computer programs will lose competitiveness.

As well, new technologies globally compete with tourism by delivering new forms of entertainment in or near the consumer's home. Intelligent agent computer programs which are a combination of pre-entered information and observed behaviours in use of online booking patterns are able to 
make suggestions on possible options for the user, thus saving time in 'surfing' the Internet. The gradual development of ambient technologies and $3 G$ mobile devices providing 'the mobile Internet' will further empower consumers by providing location- and time-dependent information, offers and services.

Tourism stakeholders share an environment of similar continuous change. The social environment, the economic, political, and legislative requirements, competition (both domestic and global), and technology continue to advance at an uncomfortable pace. Organizations evolve each day through changes in personnel, knowledge, customer base, and stockholder value but it is imperative that they evolve at the same pace as the external environment. Ultimately the companies that will survive and prosper are the ones that stretch their core competencies through innovation. Innovation can take the form of creative and successful new products, innovative solutions for achieving cost reduction and higher quality service, or innovation as the source of competitive advantage to secure greater market share. How they innovate will be context specific and depend on the resources and capabilities of the firm. The trends outlined in this paper suggest areas in which tourism stakeholders can invest to maximise their resources and capabilities that will assist them to confront future challenges and avoid strategic drift and corporate demise.

\section{Conclusions}

The paper draws out the implications for tourism of global economic, social, political, environmental and technological trends. Research on this topic has obvious relevance to global tourism in the future. With respect to particular destinations and specific tourism contexts, however, the research effort by academic researchers, consultants, government agencies etc. provides complementary valuable information at a more 'micro' level. This research can assist agencies and organisations to address the forces in the external environment, develop innovative strategies in their operations, new product development, business management and marketing activities and thereby avoid strategic drift. The issues addressed herein can for the basis of an action agenda that tourism decision makers in both the private and public sectors can undertake as part of a pro-active strategy to achieve competitive advantage internationally over the next 15 years.

Achieving competitive advantage in times of rapid change requires tourism stakeholders to have a clear understanding of the direction of change and its implications for business or destination management. Tourism stakeholders, public and private sector, need to ensure that tourism policies and planning, product development, and marketing strategies are consistent with the trends and environmental factors that are shaping the behaviour of future tourists. The paper demonstrates that research has an important role to play in helping private and public sector tourism 
organisations to 'beat the odds' against experiencing strategic drift in the context of ongoing economic, political, technological, social and environmental change.

\section{References}

Buhalis, D. (2000a), 'Trends in information technology and tourism', in WC Gartner \& DW Lime (eds), Trends in Outdoor Recreation, Leisure and Tourism, CABI Publishing, Wallingford; Cambridge, MA, pp. 47-61

Buhalis, D. (2000b), 'Tourism in an era of information technology', in B Faulkner, G Moscardo \& $\mathrm{E}$ Laws (eds), Tourism in the 21 century: lessons from experience, Continuum, London; New York, pp. 163-180.

Butler R. and P. Jones (2001) "Conclusions-problems, challenges and solutions" in A. Lockwood and S. Medlik (eds) Tourism and Hospitality in the 21st Century, Butterworth-Heinemann, Oxford.

Cetron M. (2001) "The World of Today and Tomorrow: The Global View" in A. Lockwood and S. Medlik (eds) Tourism and Hospitality in the 21st Century, Butterworth-Heinemann, Oxford.

Dwyer L. (2004) "Trends Underpinning Global Tourism in the Coming Decade" in W. Theobald (ed) Global Tourism, Butterworth-Heineman, New York.

Johnson G. and K. Scholes (1997) Exploring Corporate Strategy $4^{\text {th }}$ edition Prentice Hall, London

National Intelligence Council. (2000). Global Trends 2015: A Dialogue about the Future with Nongovernment Experts. USA: National Foreign Intelligence Board.

National Intelligence Council (2004). Mapping the Global Future. Washington, US: National Intelligence Council.

Olsen, M (1999), 'Macroforces driving change into the new millennium - major challenges for the hospitality professional', International Journal of Hospitality Management, vol. 18, no. 4, pp. 371-385.

Profound and Duerbeck, K. (2005) Natural Ingredients for Cosmetics. Centre for Promotion of Imports from Developing Countries (CBI)

Stern, N. (2006) Stern Review on the Economics of Climate Change. An Independent Review for the Treasury, United Kingdom Government. Accessed on 18 November 2006 from http://www.hm-treasury.gov.uk/

Tarlow, P. E. (2002) Tourism in the Twenty-first Century. The Futurist, 36, 48-51.

Ulbrick, D. (2006) Growing Yield in the City Holiday Market: Finding a Competitive Edge. Fifth National Conference on Tourism Futures Melbourne, December 4-6. Australia: Roy Morgan Research.

UNEP (2002). Global Environment Outlook 3 - Past, Present, and Future Perspectives, United Nations Environment Program.

Viner, D. and S. Nicholls (2005). Climate change and its implications for international tourism. In "Tourism Management Dynamics: Trends, Management and Tools". D. Buhalis and C. Costa (Eds.), Elsevier Ltd.

Weston, R., Qu, L., \& Soriano, G. (2001). The Changing Shape of Australia's Population. Victoria: Australian Institute of Family Studies - Commonwealth of Australia. 
Willmott, M \& Graham, S (2001), 'The world of today and tomorrow: the European picture', in A Lockwood \& S Medlik (eds), Tourism and Hospitality in the 21st century, ButterworthHeinemann, Oxford, pp. 29-38.

World Tourism Organisation (2002) Tourism 2020 Vision, WTO, Madrid. 